\title{
Prognostic value of co-expression of STAT3, mTOR and EGFR in gastric cancer
}

\author{
MIKITO INOKUCHI $^{1}$, TADAO MURAYAMA ${ }^{1}$, MIKIKO HAYASHI ${ }^{1}$, YOKO TAKAGI ${ }^{2}$, KEIJI KATO ${ }^{3}$, \\ MEGUMU ENJOJI $^{3}$, KAZUYUKI KOJIMA ${ }^{3}$, JIRO KUMAGAI ${ }^{4}$ and KENICHI SUGIHARA ${ }^{1}$ \\ Departments of ${ }^{1}$ Surgical Oncology, ${ }^{2}$ Translational Oncology, ${ }^{3}$ Esophagogastric Surgery, and \\ ${ }^{4}$ Human Pathology, Tokyo Medical and Dental University, Tokyo 113-8519, Japan
}

Received October 5, 2010; Accepted January 4, 2011

DOI: $10.3892 / \mathrm{etm} .2011 .187$

\begin{abstract}
Signal transducer and activator of transcription 3 (STAT3), the mammalian target of rapamycin (mTOR) and epidermal growth factor receptor (EGFR), proteins that mediate intracellular signaling related to cell growth, proliferation and differentiation, have received considerable interest as possible targets for cancer treatment. We examined whether the expression of STAT3, mTOR and EGFR correlates with clinicopathological features and patient outcome in gastric cancer. Tumor samples were obtained from 126 patients with gastric adenocarcinomas who underwent a radical gastrectomy between 1999 and 2002. The expression of phosphorylated STAT3 (p-STAT3), p-mTOR and EGFR was analyzed by immunohistochemical staining. The relations of these to clinicopathological factors and outcomes were assessed. The expression of p-STAT3 p-mTOR and EGFR positively correlated with the following variables related to tumor progression: the depth of tumor invasion (T1 vs. T2-4; $\mathrm{p}<0.001, \mathrm{p}=0.036$ and $\mathrm{p}<0.001$, respectively), lymph node involvement $(\mathrm{p}=0.008, \mathrm{p}=0.027$ and $\mathrm{p}=0.007)$ and tumor stage (I vs. II-IV; $\mathrm{p}<0.001, \mathrm{p}=0.041$ and $\mathrm{p}<0.001$ ). The expression of p-STAT3 and EGFR was significantly related to distant metastasis and recurrence $(\mathrm{p}=0.001$ and $\mathrm{p}=0.039)$, as well as significantly poorer disease-specific survival (DSS; $\mathrm{p}=0.0018$ and $\mathrm{p}=0.026$ ). The expression of $\mathrm{p}$-STAT3 was a marginally non-significant prognostic factor for DSS (hazard ratio $=2.0$, 95\% CI 0.91-4.5, $\mathrm{p}=0.082$ ). Increasing expression of $\mathrm{p}$-STAT3, p-mTOR and EGFR was associated with progressively worse DSS. Interactions among p-STAT3, p-mTOR and EGFR may play an important role in tumor progression and outcomes in patients with gastric cancer.
\end{abstract}

Correspondence to: Dr Mikito Inokuchi, Department of Surgical Oncology, Tokyo Medical and Dental University, 1-5-45 Yushima, Bunkyo, Tokyo 113-8519, Japan

E-mail: m-inokuchi.srg2@tmd.ac.jp

Key words: signal transducer and activator of transcription 3, mammalian target of rapamycin, epidermal growth factor receptor, gastric cancer

\section{Introduction}

Gastric cancer is the second most common cause of cancerrelated deaths worldwide (1). Clinical outcomes remain poor in patients with advanced gastric cancer, even after curative resection. Tyrosine kinase receptors, such as epidermal growth factor receptor (EGFR), its homolog c-erb-2 (HER2) and vascular endothelial growth factor (VEGF), have been linked to tumor progression or survival in gastric cancer (2-7). We also previously reported that EGFR or HER3 expression was correlated with tumor progression in gastric cancer (8). Several anticancer drugs designed to inhibit signaling pathways of tyrosine kinases have been evaluated in unresectable or metastatic gastric cancer, and trastuzumab (anti-HER2) has been shown to be effective (9).

The main pathways stimulated by EGFR involve phosphatidylinositol 3-kinase (PI3K)/Akt, mitogen-activated protein kinases (MAPK) and signal transducer and activator of transcription 3 (STAT3) $(10,11)$. The mammalian target of rapamycin (mTOR) is one of the targets of activated Akt. Phosphorylated mTOR (p-mTOR) stimulates initiation of translation by two targets: ribosomal p70S6 kinase (S6K1) and eukaryotic translation initiation factor $4 \mathrm{E}$ binding protein (4E-BP1). mTOR thus promotes cell growth, proliferation and differentiation $(12,13)$. We previously reported that the expression of cytoplasmic mTOR is associated with tumor progression and poorer outcomes in gastric cancer (14). STAT3 belongs to a family of cytoplasmic latent transcription factors that function as both signal transducers and activators of transcription. EGFR interacts with and activates STAT3. Phosphorylated STAT3 (p-STAT3) translocates to the nucleus and binds to recognition sequences in the promoter region of target genes, thereby regulating their transcription. Thus, aberrant STAT3 signaling has been linked to the promotion of cell cycle progression, cell survival and malignant transformation $(15,16)$. STAT3 is related to tumor progression and worse survival in gastric (17-19), colorectal $(20,21)$, lung $(22,23)$ and breast cancer (24).

The present study examined whether the expression of p-STAT3, p-mTOR and EGFR correlates with clinicopathological features and patient outcome in gastric cancer. The expression was evaluated immunohistochemically. 


\section{Patients and methods}

Patients. The study group comprised 126 patients with primary invasive (invasion deeper than the muscularis mucosa) gastric adenocarcinomas who underwent gastrectomy from January 1999 through December 2002 at the Department of Esophagogastric Surgery, Tokyo Medical and Dental University, Japan. Each tumor was classified according to the tumor-node-metastasis classification recommended by the International Union against Cancer (UICC). All patients were evaluated for recurrent disease by diagnostic imaging, including computed tomography, ultrasonography and endoscopy, every 3-6 months. The median follow-up time was 73 months (range 2-135). Ten patients who underwent R1 or R2 surgery received S-1 chemotherapy; no other patient received neoadjuvant therapy. Recurrent disease was diagnosed in 28 (24\%) of 116 patients who underwent R0 surgery and was the cause of death in these patients.

Immunohistochemical staining. Immunohistochemical staining was performed using the streptavidin-biotin method using a Histofine SAB-PO kit (Nichirei Co., Tokyo, Japan). Polyclonal rabbit anti-human antibodies against p-STAT3 (Thy705) and p-mTOR (Ser2448) were purchased from Cell Signaling Technology, Inc. (Beverly, MA, USA). Monoclonal mouse antibodies against EGFR were from Novocastra Laboratories (Newcastle upon Tyne, UK). All available H\&E-stained slides of the surgical specimens were reviewed. For each case, representative paraffin blocks were selected for immunohistochemical studies. Four-micrometer sections were cut from formalin-fixed, paraffin-embedded tissue blocks. After deparaffinization and rehydration, antigen retrieval treatment was performed at $121^{\circ} \mathrm{C}$ (autoclave) for $5 \mathrm{~min}$ in $10 \mathrm{nmol} / \mathrm{l}$ sodium citrate buffer ( $\mathrm{pH} 9.0)$, followed by treatment with $3 \%$ hydrogen peroxide for $15 \mathrm{~min}$ to quench endogenous peroxidase activity. Non-specific binding was blocked by treating the slides with 5\% EzBlock (including 5\% normal goat serum and $0.1 \%$ Tween-20) for $60 \mathrm{~min}$ at room temperature. The slides were incubated with a primary antibody (dilution 1:50) overnight at $4^{\circ} \mathrm{C}$. Immunodetection was performed by the conventional streptavidin-biotin method with a Nichirei SAB-PO kit (Nichirei Co.). The slides were counterstained with $1 \%$ Mayer's hematoxylin.

Two independent observers blinded to the patients' clinical information examined all of the slides with an optical microscope. Positive expression was defined as $>10 \%$ of the cells with nuclear staining for p-STAT3 (17) or $>10 \%$ of the cells with cytoplasmic staining for p-mTOR, as previously described (14). Positive EGFR expression was defined as $>10 \%$ of the cells with moderate or strong membrane staining.

Statistical analysis. The Chi-square test was used to test possible associations of the expression of p-STAT3, p-mTOR and EGFR with clinicopathological factors. It was also used to assess correlations between each type of expression. KaplanMeier curves were plotted to assess the effects of each type of expression on disease-specific survival (DSS). Survival curves were compared using the log-rank test. P-values of $<0.05$ were considered to indicate statistical significance. Multivariate proportional Cox models were used to assess the
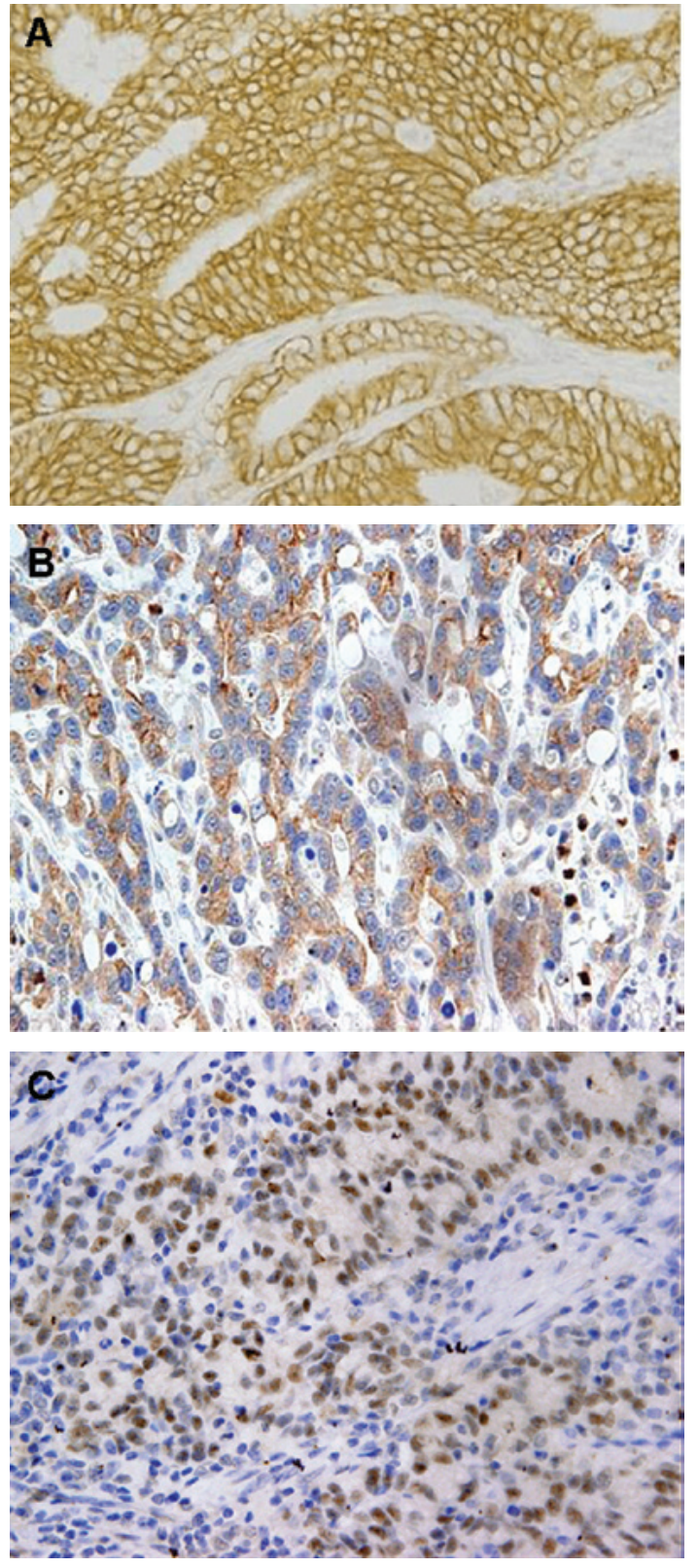

Figure 1. Representative gastric carcinomas showing immunostaining for (A) p-STAT3 predominantly in the nucleus, (B) immunostaining for p-mTOR predominantly in the cytoplasm and (C) immunostaining for EGFR predominantly in the membrane; magnification, $\mathrm{x} 400$.

prognostic significance of all expression levels and of several clinicopathological factors. Statistical analysis was performed with the use of SPSS Base, version 11.0 and SPSS Advanced Models, version 11.0 (SPSS Inc., Chicago, IL, USA) software.

\section{Results}

Expression of nuclear p-STAT3, cytoplasmic p-mTOR and membranous EGFR was found in $52(41 \%), 81(64 \%)$ and 37 (29\%) tumors, respectively (Fig. 1). All three types of expression were observed in $16(13 \%)$ tumors, while $28(22 \%)$ tumors showed no expression. The expression of p-STAT3 significantly correlated with that of mTOR $(p=0.035)$. EGFR expression correlated slightly, but not significantly with $\mathrm{p}$-STAT3 and mTOR expression $(\mathrm{p}=0.060$ and $\mathrm{p}=0.054)$. 


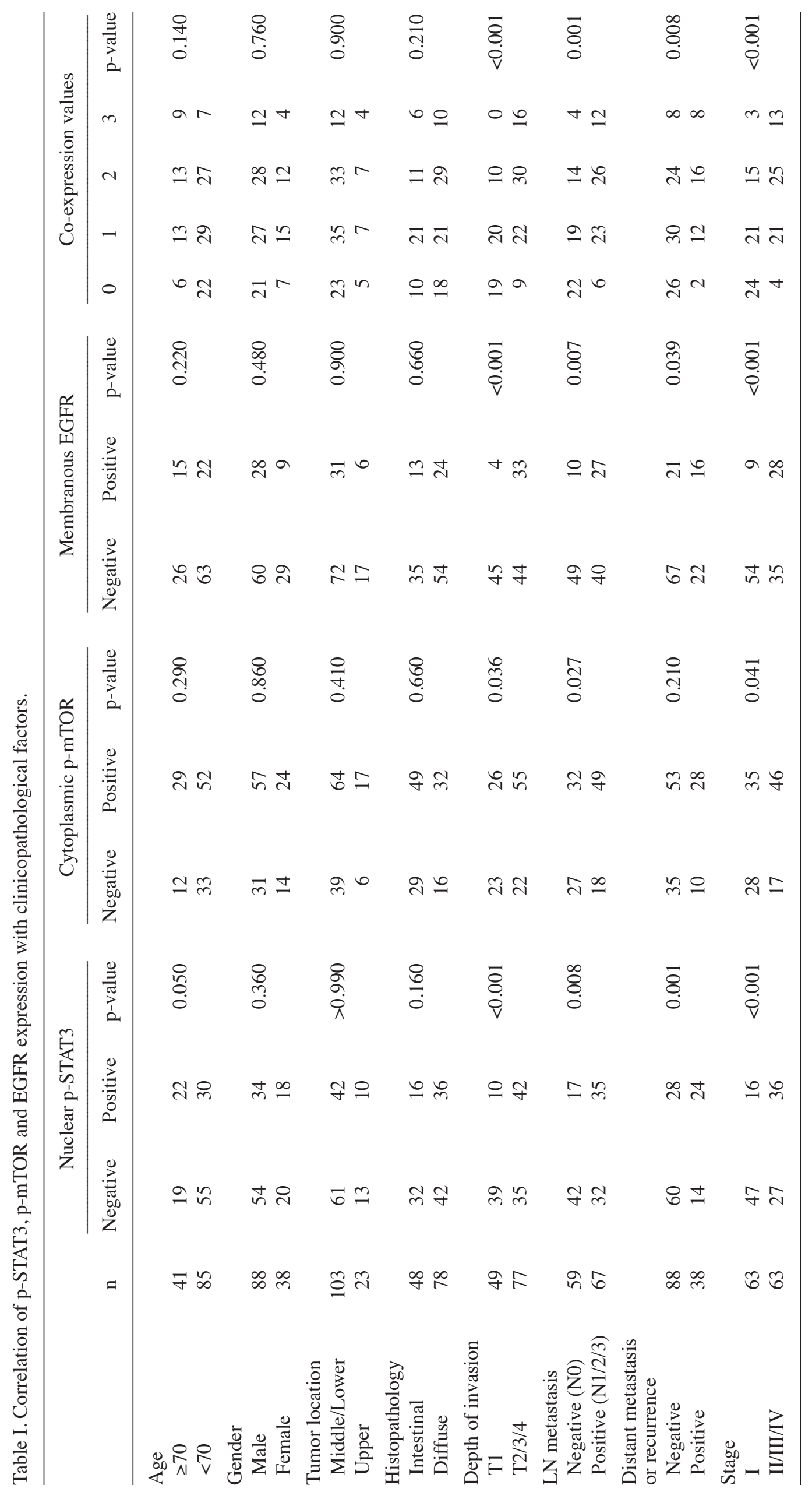


A

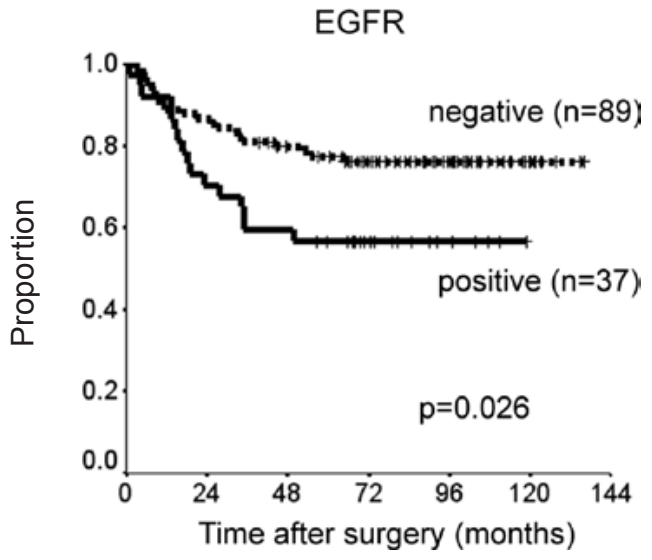

B

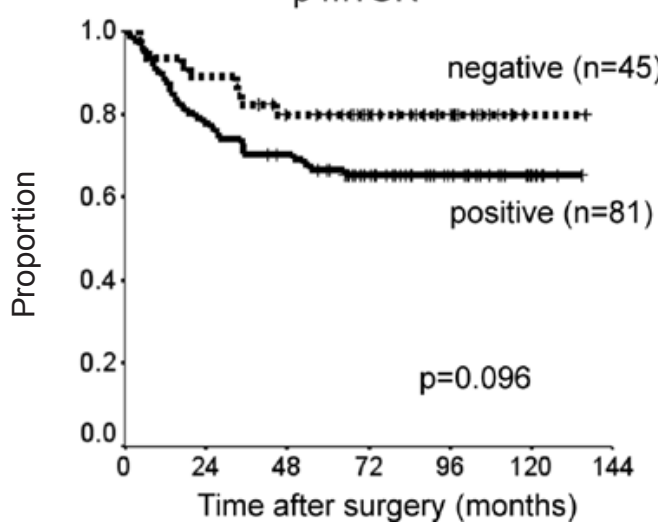

C

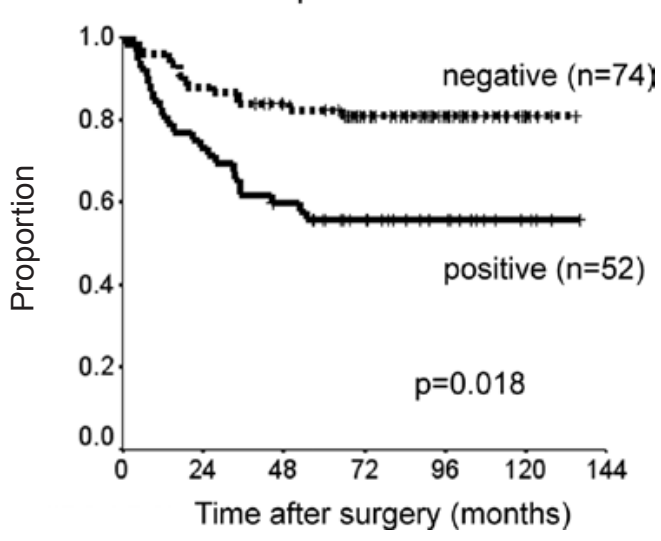

Figure 2. Kaplan-Meier curves comparing disease-specific survival of patients with expression of (A) EGFR, (B) p-mTOR and (C) p-STAT3.

Immunoreactivity for p-STAT3, p-mTOR and EGFR was present in advanced cancer. Each type of expression positively correlated with the depth of tumor invasion (T1 vs. T2-4; $\mathrm{p}<0.001, \mathrm{p}=0.036$ and $\mathrm{p}<0.001$, respectively) and lymph node involvement $(\mathrm{p}=0.008, \mathrm{p}=0.027$ and $\mathrm{p}=0.007)$. Each type of expression was also significantly associated with UICC stage (I vs. II-IV; $\mathrm{p}<0.001, \mathrm{p}=0.041$ and $\mathrm{p}<0.001$ ). Expression of p-STAT3 or EGFR was significantly related to distant metastasis or recurrence $(\mathrm{p}=0.001$ and $\mathrm{p}=0.039)$, whereas the expression of $\mathrm{p}$-mTOR was not $(\mathrm{p}=0.21)$. No type of expression significantly correlated with histological type or gender, although p-STAT3 expression tended to be associated with older age $(p=0.050)$. Co-expression of $p$-STAT3, $p$-mTOR and EGFR correlated significantly with tumor depth, lymph node
Table II. Prognostic factors in a multivariate Cox proportional hazards regression model.

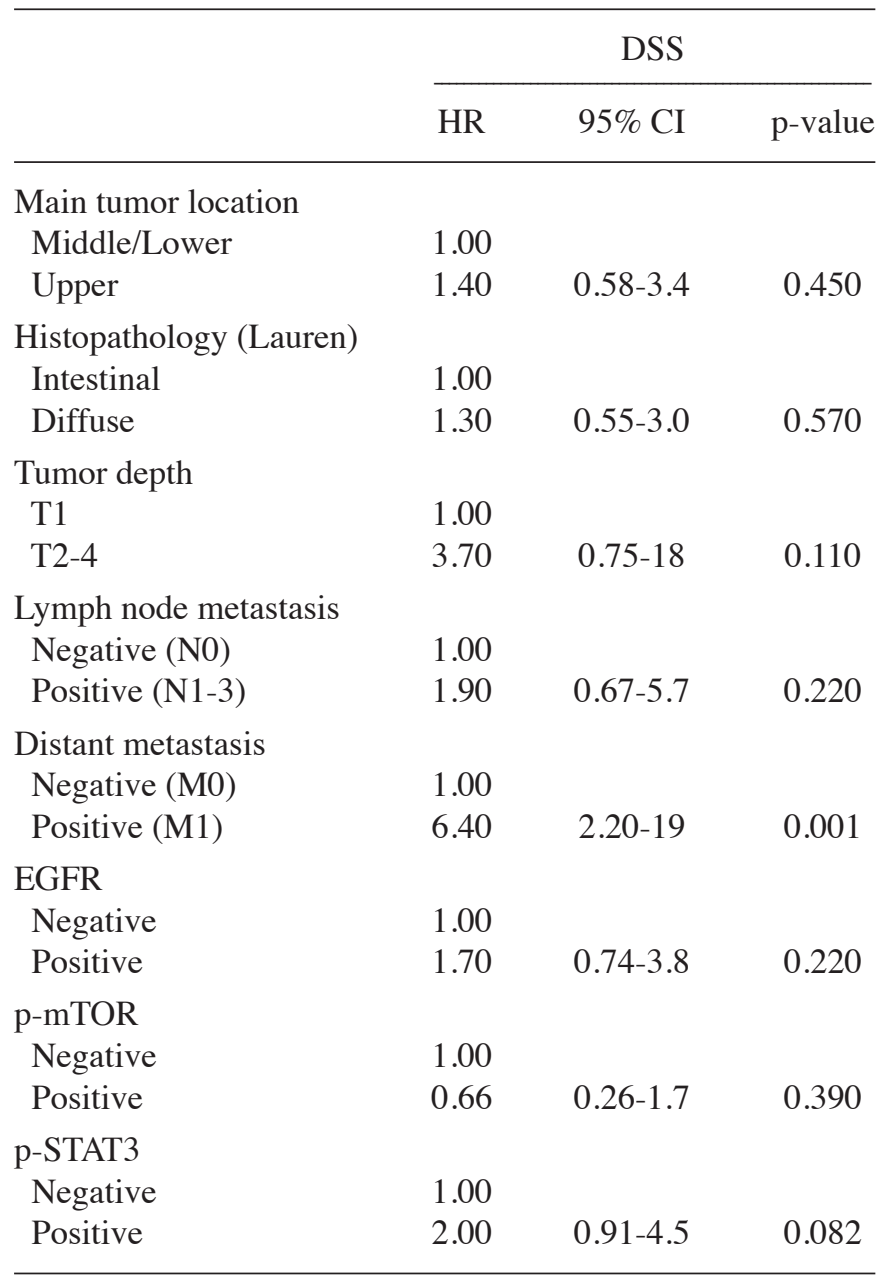

involvement, UICC stage and distant metastasis or recurrence $(\mathrm{p}<0.001, \mathrm{p}=0.001, \mathrm{p}<0.001$ and $\mathrm{p}=0.008$, respectively) (Table I).

Patients with p-STAT3 or EGFR expression had significantly shorter DSS than did those without such expression $(\mathrm{p}=0.0018$ and $\mathrm{p}=0.026)$. There was a slight, but insignificant association between p-mTOR expression and shorter DSS $(p=0.096)$ (Fig. 2). The prognostic relevance of the expression of each protein was assessed using a multivariate proportional hazards model adjusted for several clinical factors (main location of tumor, histological type, depth of tumor, lymph node metastasis and distant metastasis) (Table II). Expression of p-STAT3 was a marginally insignificant prognostic factor for DSS [hazard ratio (HR) $=2.0,95 \%$ CI 0.91-4.5, $\mathrm{p}=0.082$ ). Distant metastasis was the only independent prognostic factor for DSS (HR=6.4, 95\% CI 2.2-19, $\mathrm{p}=0.001)$. DSS was reduced with increased co-expression of p-STAT3, p-mTOR and EGFR (Fig. 3). DSS at 5 years was $93 \%$ in patients with no expression of the proteins, $76 \%$ in patients with positive expression of one type of protein, $60 \%$ in those with positive expression of two of the proteins and 50\% in those with positive expression of all three proteins. Survival was significantly longer in patients with no positive expression than in those with positive expression of two or all three proteins (none vs. all: $\mathrm{p}=0.0012$; none vs. two: $\mathrm{p}=0.0047$ ). 


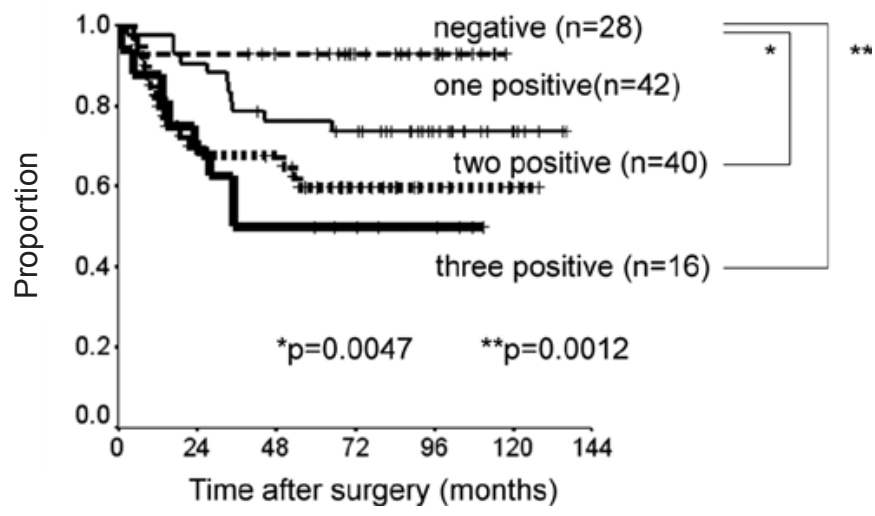

Figure 3. Kaplan-Meier curves of the disease-specific survival of four subgroups classified according to the co-expression of p-STAT3, p-mTOR and EGFR.

\section{Discussion}

The present study showed that the co-expression of p-STAT3, p-mTOR and EGFR, members of the EGFR signaling pathway, was significantly associated with tumor progression and less favorable survival in gastric cancer. The expression levels of these proteins appeared to be related to clinical outcomes, but were not independent prognostic factors. In addition, the co-expression of these proteins was associated with poorer DDS.

STAT3 translocates to the nucleus, where it activates gene transcription and modulates cell proliferation, apoptosis and differentiation. Therefore, nuclear expression of p-STAT3, the activated form of STAT3, may be more intimately related to tumor progression than its cytoplasmic expression. Immunohistochemically, STAT3 is detected much more frequently in gastric cancer than in surrounding normal tissue (18). In the present study, p-STAT3 expression was rarely detected in normal gastric mucosa. Nuclear expression of p-STAT3 was significantly associated with tumor progression and clinical outcomes in gastric cancer, whereas cytoplasmic expression of p-STAT3 was not (data not shown). Several studies showed that immunohistochemical staining for p-STAT3 or STAT3 was related to poor survival in gastric cancer, without specifying the site of staining. Park et al reported that p-STAT3 was expressed predominantly in the nucleus in colon cancer. However, when they analyzed nuclear and cytoplasmic expression together, p-STAT3 was found to be associated with clinical stage (21). In breast cancer, STAT3 was detected mainly in the cytoplasm and its expression was related to the overall 5-year survival rate (24). This discrepancy in the location of staining may be attributed to differences in the type of cancer or in the antibodies used for immunostaining. Lee et al found that immunohistochemical staining for nuclear p-STAT3 was an independent prognostic factor in gastric cancer. The prognostic value appeared to be enhanced when p-STAT3 and matrix metalloproteinase-10 (MMP-10) were combined (19). STAT3 activation is implicated in the modulation of MMP-10 activity. Several molecular targets involving the STAT3 signaling pathway may have a substantial effect on patient outcome in gastric cancer.
EGFR expression has been considered a prognostic factor for patients with gastric cancer $(2,3)$. In the present study, EGFR expression was significantly associated with tumor progression and poor survival in gastric cancer, but was not an independent prognostic factor. EGFR consists of an extracellular ligand-binding domain, a transmembrane domain and an intracytoplasmic tyrosine kinase domain. EGFR expression is detected mainly in the membrane of cancer cells, but has also been detected in the nucleus in several studies $(25,26)$. The EGFR antibodies used in the present study were rarely detected in the cytoplasm or nucleus. EGFR interacts with STAT3 in the nucleus, leading to transcriptional activation of inducible nitric oxide synthases (26). Several inhibitors of EGFR have been used to treat unresectable or recurrent gastric cancer, but provided no benefit in such patients or in those with colorectal or lung cancer (27). Inhibition of EGFR alone may be inadequate and synchronous inhibition of downstream substrates, such as mTOR and STAT3, may be essential for improving outcomes in gastric cancer.

We previously reported that the cytoplasmic expression of p-mTOR positively correlated with tumor progression and survival in gastric cancer. However, few studies have demonstrated the impact of mTOR expression on survival in patients with cancer (28). Akt, which is an upstream regulator of mTOR, was not associated with outcomes in patients with several types of cancer in previous studies, including ours $(14,29,30)$. Therefore, activation of Akt/mTOR alone may not have an impact on tumor growth or patient survival. Ma et al demonstrated that mTOR activates STAT3/p63/Jagged signal cascade in vitro (31). In the present study, p-mTOR expression correlated significantly with p-STAT3 expression. Activation of STAT3, by not only EGFR/STAT3 but also mTOR/STAT3 signaling, may lead to poor survival in gastric cancer.

In conclusion, co-expression of p-STAT3, p-mTOR and EGFR may play an important role in tumor progression and clinical outcomes in patients with gastric cancer.

\section{References}

1. Parkin DM, Bray F, Ferlay J and Pisani P: Global cancer statistics, 2002. CA Cancer J Clin 55: 74-108, 2005.

2. Yonemura Y, Sugiyama K, Fushida S, Kamata T, Ohoyama S, Kimura H, Yamaguchi A and Miyazaki I: Tissue status of epidermal growth factor and its receptor as an indicator of poor prognosis in patients with gastric cancer. Anal Cell Pathol 3: 343-350, 1991 .

3. Hirono Y, Tsugawa K, Fushida S, Ninomiya I, Yonemura Y, Miyazaki I, Endou Y, Tanaka M and Sasaki T: Amplification of epidermal growth factor receptor gene and its relationship to survival in human gastric cancer. Oncology 52: 182-188, 1995.

4. Allgayer H, Babic R, Gruetzner KU, Tarabichi A, Schildberg FW and Heiss MM: c-erbB-2 is of independent prognostic relevance in gastric cancer and is associated with the expression of tumorassociated protease systems. J Clin Oncol 18: 2201-2209, 2000.

5. García I, Vizoso F, Martín A, Sanz L, Abdel-Lah O, Raigoso P and García-Muñiz JL: Clinical significance of the epidermal growth factor receptor and HER2 receptor in resectable gastric cancer. Ann Surg Oncol 10: 234-241, 2003.

6. Hirashima Y, Yamada Y, Matsubara J, Takahari D, Okita N, Takashima A, Kato K, Hamaguchi T, Shirao K, Shimada Y, Taniguchi $\mathrm{H}$ and Shimoda T: Impact of vascular endothelial growth factor receptor 1,2, and 3 expression on the outcome of patients with gastric cancer. Cancer Sci 100: 310-315, 2009.

7. Jüttner S, Wissmann C, Jöns T, Vieth M, Hertel J, Gretschel S, Schlag PM, Kemmner W and Höcker M: Vascular endothelial growth factor-D and its receptor VEGFR-3: two novel independent prognostic markers in gastric adenocarcinoma. J Clin Oncol 24: 228-240, 2006. 
8. Hayashi M, Inokuchi M, Takagi Y, Yamada H, Kojima K, Kumagai J, Kawano $\mathrm{T}$ and Sugihara K: High expression of HER3 is associated with a decreased survival in gastric cancer. Clin Cancer Res 14: 7843-7849, 2008

9. Bang YJ, van Cutsem E, Feyereislova A, Chung HC, Shen L, Sawaki A, Lordick F, Ohtsu A, Omuro Y, Satoh T, Aprile G, Kulikov E, Hill J, Lehle M, Rüschoff J, Kang YK; for the ToGA Trial Investigators: Trastuzumab in combination with chemotherapy versus chemotherapy alone for treatment of HER2-positive advanced gastric or gastro-oesophageal junction cancer (ToGA): a phase 3, open-label, randomised controlled trial. Lancet 376: 687-697, 2010.

10. Grandis JR, Drenning SD, Chakraborty A, Zhou MY, Zeng Q, Pitt AS and Tweardy DJ: Requirement of Stat3 but not Stat1 activation for epidermal growth factor receptor-mediated cell growth in vitro. J Clin Invest 102: 1385-1392, 1998

11. Coffer PJ and Kruijer W: EGF receptor deletions define a region specifically mediating STAT transcription factor activation. Biochem Biophys Res Commun 210: 74-81, 1995.

12. Schmelzle T and Hall MN: TOR, a central controller of cell growth. Cell 103: 253-262, 2000.

13. Petroulakis E, Mamane Y, Le Bacquer O, Shahbazian D and Sonenberg N: mTOR signaling: implications for cancer and anticancer therapy. Br J Cancer 94: 195-199, 2006

14. Murayama T, Inokuchi M, Takagi Y, Yamada H, Kojima K, Kumagai J, Kawano $\mathrm{T}$ and Sugihara K: Relation between outcomes and localisation of p-mTOR expression in gastric cancer. Br J Cancer 100: 782-788, 2009.

15. Bowman T, Garcia R, Turkson J and Jove R: STATs in oncogenesis. Oncogene 15: 2474-2488, 2000.

16. Levy DE and Lee CK: What does Stat3 do? J Clin Invest 109: 1143-1148, 2002.

17. Yakata Y, Nakayama T, Yoshizaki A, Kusaba T, Inoue K and Sekine I: Expression of p-STAT3 in human gastric carcinoma: significant correlation in tumour invasion and prognosis. Int $\mathrm{J}$ Oncol 30: 437-442, 2007

18. Kim DY, Cha ST, Ahn DH, Kang HY, Kwon CI, Ko KH, Hwang SG, Park PW, Rim KS and Hong SP: STAT3 expression in gastric cancer indicates a poor prognosis. J Gastroenterol Hepatol 24: 646-651, 2009

19. Lee J, Kang WK, Park JO, Park SH, Park YS, Lim HY, Kim J, Kong J, Choi MG, Sohn TS, Noh JH, Bae JM, Kim S, Lim do H, Kim KM and Park CK: Expression of activated signal transducer and activator of transcription 3 predicts poor clinical outcome in gastric adenocarcinoma. APMIS 117: 598-606, 2009.

20. Kusaba T, Nakayama T, Yamazumi K, Yakata Y, Yoshizaki A, Inoue K, Nagayasu T and Sekine I: Expression of p-STAT3 in human colorectal adenocarcinoma and adenoma; correlation with clinicopathological factors. J Clin Pathol 58: 833-838, 2005 .
21. Park JK, Hong R, Kim KJ, Lee TB and Lim SC: Significance of p-STAT3 expression in human colorectal adenocarcinoma. Oncol Rep 20: 597-604, 2008.

22. Kim HS, Park YH, Lee J, Ahn JS, Kim J, Shim YM, Kim JH, Park K, Han J and Ahn MJ: Clinical impact of phosphorylated signal transducer and activator of transcription 3, epidermal growth factor receptor, p53, and vascular endothelial growth factor receptor 1 expression in resected adenocarcinoma of lung by using tissue microarray. Cancer 116: 676-685, 2010.

23. Haura EB, Zheng Z, Song L, Cantor A and Bepler G: Activated epidermal growth factor receptor-Stat-3 signaling promotes tumor survival in vivo in non-small cell lung cancer. Clin Cancer Res 11: 8288-8294, 2005

24. Sheen-Chen SM, Huang CC, Tang RP, Chou FF and Eng HL: Prognostic value of signal transducers and activators of transcription 3 in breast cancer. Cancer Epidemiol Biomarkers Prev 17: 2286-2290, 2008.

25. Lin SY, Makino K, Xia W, Matin A, Wen Y, Kwong KY, Bourguignon L and Hung MC: Nuclear localization of EGF receptor and its potential new role as a transcription factor. Nat Cell Biol 3: 802-808, 2001.

26. Lo HW, Hsu SC, Ali-Seyed M, Gunduz M, Xia W, Wei Y, Bartholomeusz G, Shih JY and Hung MC: Nuclear interaction of EGFR and STAT3 in the activation of the iNOS/NO pathway. Cancer Cell 7: 575-589, 2005.

27. Pinto C, Di Fabio F, Barone C, Siena S, Falcone A, Cascinu S, Rojas Llimpe FL, Stella G, Schinzari G, Artale S, Mutri V, Giaquinta S, Giannetta L, Bardelli A and Martoni AA: Phase II study of cetuximab in combination with cisplatin and docetaxel in patients with untreated advanced gastric or gastro-oesophageal junction adenocarcinoma (DOCETUX study). Br J Cancer 101: 1261-1268, 2009.

28. Zhou X, Tan M, Stone Hawthorne V, Klos KS, Lan KH, Yang Y, Yang W, Smith TL, Shi D and Yu D: Activation of the Akt/ mammalian target of rapamycin/4E-BP1 pathway by ErbB2 overexpression predicts tumor progression in breast cancers. Clin Cancer Res 10: 6779-6788, 2004.

29. Nam SY, Lee HS, Jung GA, Choi J, Cho SJ, Kim MK, Kim WH and Lee BL: Akt/PKB activation in gastric carcinomas correlates with clinicopathologic variables and prognosis. APMIS 111: 1105-1113, 2003.

30. Chadha KS, Khoury T, Yu J, Black JD, Gibbs JF, Kuvshinoff BW, Tan D, Brattain MG and Javle MM: Activated Akt and Erk expression and survival after surgery in pancreatic carcinoma. Ann Surg Oncol 13: 933-939, 2006.

31. Ma J, Meng Y, Kwiatkowski DJ, et al: Mammalian target of rapamycin regulates murine and human cell differentiation through STAT3/p63/Jagged/Notch cascade. J Clin Invest 120: 103-114, 2010. 